EMBRYARIDDLE
Aeronautical University

SCHOLARLY COMMONS

\section{International Journal of Aviation,} Aeronautics, and Aerospace

\title{
Open-ended capstone project: designing and manufacturing of a low-cost carbon fiber reinforced composite suborbital rocket payload housing using a 3D printed core
}

\author{
Garam Kim \\ Purdue University, yaram0229@gmail.com \\ Sergey Dubikovsky \\ Purdue University, sdubikov@purdue.edu \\ Peng Hao Wang \\ Purdue University - Main Campus, pwang@purdue.edu \\ Ronald Sterkenburg \\ Purdue University, sterkenr@purdue.edu
}

Follow this and additional works at: https://commons.erau.edu/ijaaa

Part of the Educational Methods Commons, Materials Science and Engineering Commons, and the Structures and Materials Commons

\section{Scholarly Commons Citation}

Kim, G., Dubikovsky, S., Wang, P., \& Sterkenburg, R. (2020). Open-ended capstone project: designing and manufacturing of a low-cost carbon fiber reinforced composite suborbital rocket payload housing using a 3D printed core. International Journal of Aviation, Aeronautics, and Aerospace, 7(2). https://doi.org/ 10.15394/ijaaa.2020.1492

This Special Purpose Document is brought to you for free and open access by the Journals at Scholarly Commons. It has been accepted for inclusion in International Journal of Aviation, Aeronautics, and Aerospace by an authorized administrator of Scholarly Commons. For more information, please contact commons@erau.edu. 


\section{Composite material}

Advanced composite material is a combination of a high-performance fiber reinforcement and a polymer matrix. Advanced composite materials are well known for their high performance and light weight (Peters, 2013). Therefore, advanced composites are often used in various industries, especially the aerospace and aviation industries. In modern aircraft, traditional aluminum or steel structures have been gradually replaced by composite materials. For example, Boeing 787, one of the most recent aircrafts, consists of more than $50 \%$ of structural composite materials by weight (Bossi, 2006). Traditional composite part manufacturing processes require the use of manufacturing molds. The composite material is laid up on the manufacturing molds, followed by the application of pressure and heat to consolidate and cure the composite material on the mold. Molds used for composite part manufacturing are often made of aluminum, steel, tooling board, or a composite material (Campbell, 2003). Building a composite part manufacturing mold is often a complicated process with high cost. This is especially true for low number production processes such as prototype manufacturing, where building a fully functional composite part manufacturing mold is not cost effective.

\section{Additive Manufacturing Technology}

The rapid development of additive manufacturing technology has allowed people to 3D print with various kinds of material. The additive manufacturing process builds parts by layers, resulting in a high degree of freedom for the part's geometrical shape. Additive manufacturing technology is utilized in many ways in composite part manufacturing. Composite material can be directly 3D printed. Tian et al. (2016) studied continuous carbon fiber reinforced polylactic acid (PLA) composite additive manufacturing using the fused deposition modeling (FDM) process. Tian et al. (2016) added a continuous fiber feeding pipe to the extruder and allowed PLA filament and continuous fiber feed into the extruder together. Tian et al. (2016) reported that printing temperature and pressure were critical and should be optimized to achieve the proper mechanical strength of the printed part. Brenken et al. (2019) developed a composite additive manufacturing research instrument (CAMRI) which uses an extrusion deposition additive manufacturing (EDAM) process to print various types of thermoplastic polymer with short fibers. Direct composite part printing is not the only solution, there are other ways to apply additive manufacturing technology to the composite part manufacturing process. Molds for composite part manufacturing are often additively manufactured using various materials. Since composite prepreg materials are cured at an elevated temperature, printed materials that can withstand high temperatures are often used to fabricate molds for composite parts. Polyetherimide (PEI), also known as Ultem, is one of the commonly used 3D printing materials in the marketplace for composite part molds (Schniepp, n.d.). Eduardo et al. (2017) fabricated composite part manufacturing molds with a high-performance thermoplastic polymer with short carbon fiber using CAMRI. Eduardo et al. (2017) reported that the printed mold was able to be used for composite part manufacturing 
processes even the composite material needed to be cured at an elevated temperature with high pressure. Liquid soluble materials, such as polyvinyl alcohol (PVA) and high impact polystyrene (HIPS) are used to print composite molds with complex geometries (Benchoff, 2017). Composite materials are laid up on a $3 \mathrm{D}$ printed soluble material, and the mold is dissolved into the liquid after the composite part is cured. This process allows to make composite parts with complex geometries. The core material for composite sandwich structures also can be additively manufactured. Li \& Wang (2017) additively manufactured sandwich cores with different pattern using an acrylic-based photopolymer. Li \& Wang (2017) bonded a carbon fiber reinforced polymer face sheet on both sides of the printed core to create a composite sandwich structure. Li \& Wang (2017) studied how different patterned cores affected the flexural stiffness and flexural strength of the structure. Galatas et al. (2018) printed sandwich cores with acrylonitrile butadiene styrenecarbon (ABS) using an FDM type 3D printer. Galatas et al. (2018) bonded woven carbon fiber fabric composite to the core using a wet layup technique to make a composite sandwich structure. Galatas et al. (2018) showed that the composite sandwich structure had a significantly improved strength and stiffness compared to a bare 3D printed part. Additive manufacturing of flexible and stretchable elastomer also can be used in a composite part manufacturing process. Kim et al. (2019) printed a thermoplastic polyurethane (TPU) bladder for bladder assisted composite manufacturing (BACM) process. Kim et al. (2019) showed that a 3D printed bladder could be used in the BACM process to make composite parts with low void content that was compatible to autoclave manufactured composite parts.

\section{Project-Based Learning}

Problem-Based Learning (PBL) is used in many educational programs to promote learning and provide deeper understanding of major topics. PBL is utilized in many undergraduate programs from aeronautics and astronautics, where students design and manufacture complex functional space products and systems, to civil Engineering, to computing (Brodeur et al., Ellis et al., 1998; 2002; Mclntyre, 2002). Students are tasked to work on complex multidisciplinary, some even industry-sponsored or international, projects with no obvious and single solution. An instructor changes his or her role from a lecturer to a mentor (Maudsley, 1999). Strict memorization is replaced with reflection, which facilitates higher-order thinking (Hmelo \& Ferrari, 1997). At the same time, PBL methodology increases pressure on students, because some of them have difficult time to deal with complexity of projects and constantly changing schedules, goals, limitations, scope, and planning (Dubikovsky, 2016). However, the lack of developed acceptance of ever-changing world and adaptation to it will compromise successful students' preparation their future careers in industry (Koen, 2003).

The described project is one of various examples of project-based learning performed at the Purdue University's School of Aviation and Transportation Technology, more specific by students from Aeronautical 
Engineering Technology (AET) program. This particular project was finished in collaboration with a faculty member and students from Purdue University Aeronautical and Astronautics Engineering (AAE), who acted as customers. They participated in product definition and conceptual phase of the project. The detailed design and manufacturing part of project was accomplished by the AET students.

\section{EXOS Aerospace and Rocket Payload Housing}

Many disciplines of scientific research are interested in conducting experiments in microgravity conditions. Testing conducted in this environment has yielded advances in the fields of biotechnology, fluid physics, materials science, combustion science, and fundamental physics (Salim et al., 2010). However, this type of research is cost prohibitive for most individuals or organizations (Coopersmith, 2011; US Fed News Service, 2011). EXOS Aerospace is among a handful of companies trying to revolutionize the process of making the microgravity environment available to a much broader clientele through its sounding rocket program. EXOS Aerospace aims to provide a microgravity research environment to their customers by providing access to a suborbital microgravity environment with an expedited launch and recovery sequence. EXOS had their first successful sounding flight in 2011; a flight which included an experiment from Purdue University. For this flight, the cargo/equipment rack was made of aluminum extrusions which have been determined to be both too heavy and overly limited in design flexibility to meet the goals of the company. To this end, the EXOS Corporation needed a new method of mounting and containing experiments. The new method had to be light-weight, structurally robust, modular, and reusable. The EXOS payload container is a significant piece of hardware. The entire design and purpose of the EXOS rocket is to carry a payload of experiments to be exposed to microgravity. Therefore, EXOS required a lightweight, robust, and modular container which can protect, house, and organize smaller experiments based on the $10 \mathrm{~cm}$ CubeSat box they plan to launch into the mesosphere at a greatly reduced cost to increase customer accessibility (Hicks, 2001). Specifically, EXOS set the following requirements for the rocket payload housing; 1) the container shall be able to carry a maximum payload of $13.61 \mathrm{~kg}$ per experiment tray, 2) the container must be able to withstand a maximum inertial load of $+/-4 \mathrm{~g}, 3$ ) the container sections must be able to house one $10 \mathrm{~cm} 3$ CubeSat experiment, and 4) the container must meet the overall dimensions of $50.8 \mathrm{~cm}$ in diameter and $101.6 \mathrm{~cm}$ in height. To manufacture a rocket payload housing which satisfied all requirements for the EXOS rocket, a fiber reinforced composite material was utilized due to its high performance and lightweight. However, composite part manufacturing processes require a high manufacturing cost and time, especially for the fabrication of the required molds. In this paper, the authors introduced a low-cost composite part manufacturing process that did not require the building of a composite part manufacturing mold. The authors demonstrated that a carbon fiber reinforced composite rocket payload housing could be manufactured with an additively manufactured PLA core. The payload housing 
manufacturing process consisted of part design, structural performance simulation, core printing and joining, and composite material layup and curing.

\section{Designing and Manufacturing Process}

Payload Housing Designing Process

The goal of the payload housing designing process was to create a housing design that was flexible (in terms of modularity) and easy to work with to provide effective utility. At the same time, the payload housing needed to be light and durable enough to withstand the weight of the payloads and forces due to the rocket's acceleration. A container that had close tolerances to the allowable dimensions (the interior of the rocket) would maximize the available space for the payload (Sairajan \& Nair, 2011). Since the rocket body was cylindrical in shape, the payload housing was also designed to have a cylindrical shape. The flat sections, which allowed clearance for a wire bundle had openings to allow wiring to be inserted as well as a means to view inside each compartment. Being cylindrical in nature, platters or "decks" could be inserted into the container in numerous configurations. This allowed for individual experiments to efficiently use the space within the payload container. Figure 1 shows schematic drawing of a payload housing section.
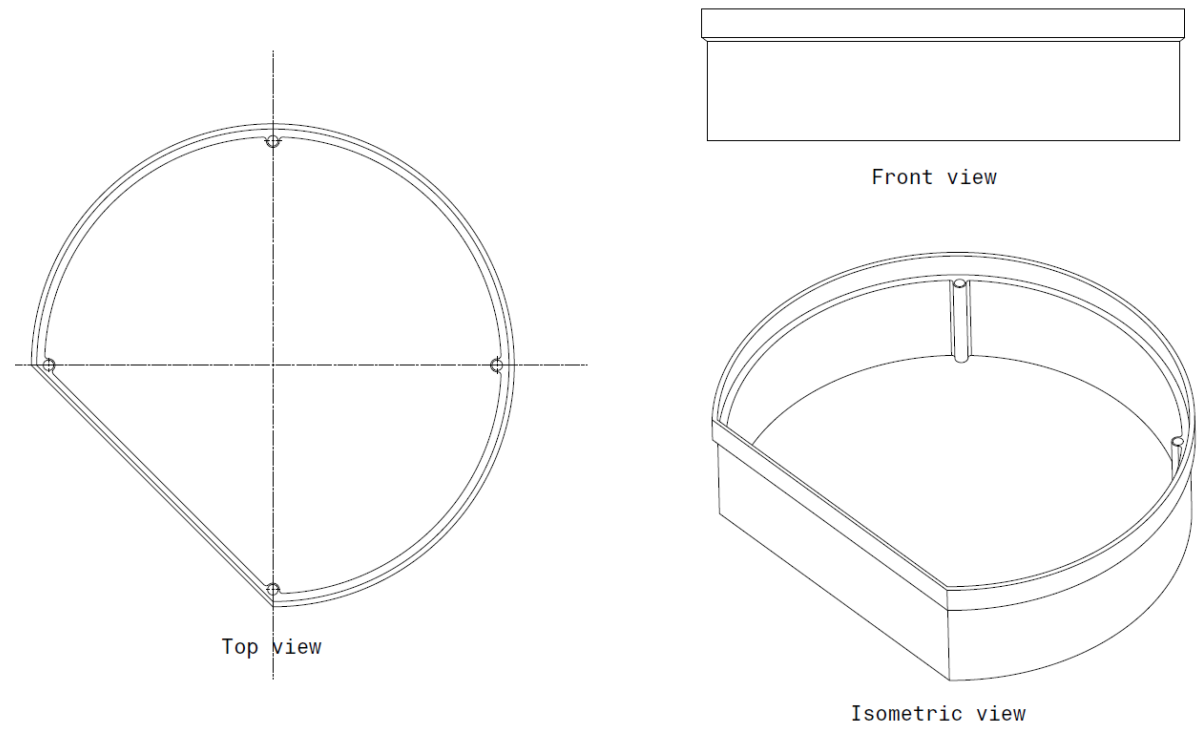

Figure 1. Schematic drawing of the rocket payload housing.

The payload housing was designed as a stage module which could have multiple layers to increase space for instruments. Depending on how much space was needed, more stages could be added or removed. Stackable payload containers of various heights could be swapped out to form various configurations. Payload container sections were held together with four through-bolts (skewers) that fasten a top plate to an adapter plate. The adapter plate was the interface between the rocket's bulkhead upon which the payload 
sections were built. It provided a seating surface for the bottom payload container as well as threads for the skewers to fasten into. The skewers only pull the top plate to the adapter plate, and only pass through each payload section via passage holes. The resulting compression kept each payload section seated. Figure 2 shows the rocket payload housing assembly design (a) before and (b) after assembly.

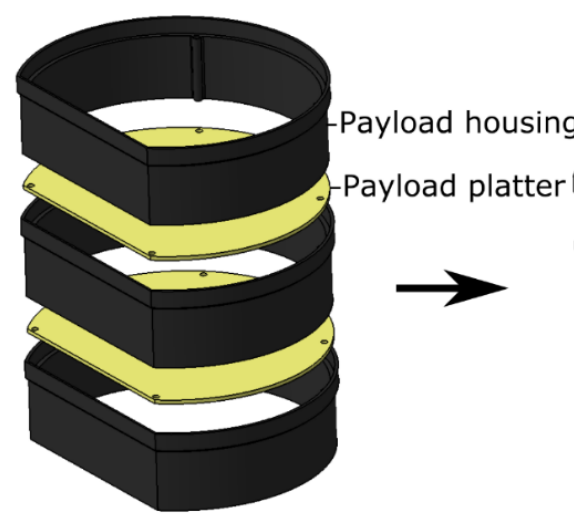

(a)
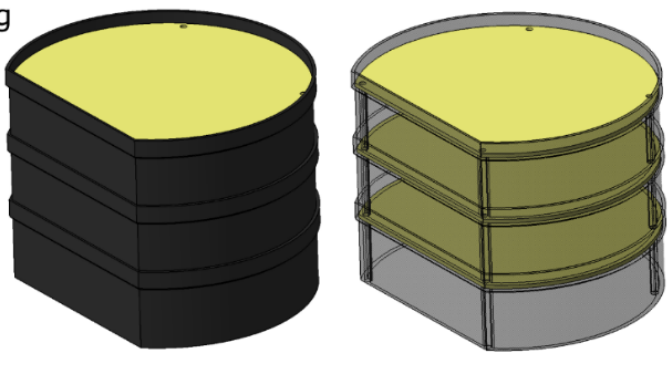

(b)

Figure 2. The rocket payload housing assembly design (a) before and (b) after assembly.

After the payload housing was designed, a finite element analysis (FEA) was performed to ensure the design satisfied the structural requirements for the application. The number of required composite plies was also decided during this process. Based on the FEA result, it was decided that four plies of carbon fiber woven fabric composite (plain weave) were needed. Figure 3 shows the FEA result (Von Mises stress and displacement) in the case that 45.36 $\mathrm{kg}$ of weight is applied to the payload housing. 


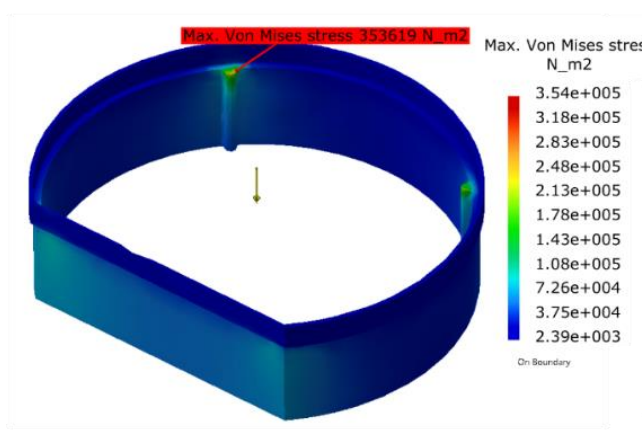

(a)

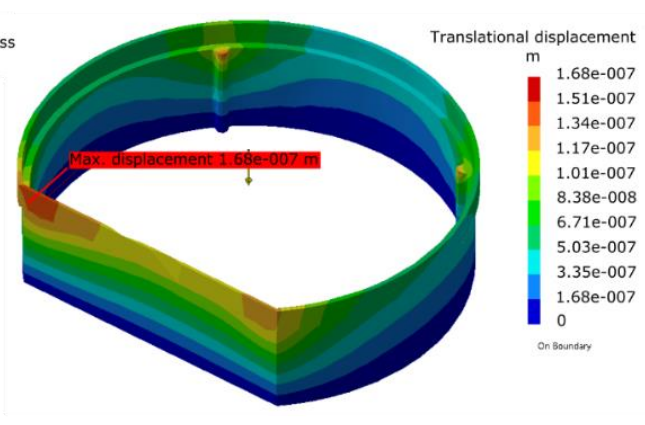

(b)

Figure 3. FEA result of the payload housing design when $100 \mathrm{lbs}$. weight is applied. (a) Von Mises stress and (b) displacement.

\section{Payload Housing Manufacturing Process}

Due to the size limitation of the 3D printer, the authors could not print a full-scale container section without splitting the core into sections. Therefore, the core was split into four sections when it was printed. The joining areas of each section were modified to have a larger bonding area. A MakerBot Z18 3D printer with a MakerBot Smart Extruder + was used to print the core. Table 1 shows print settings used to print the payload housing core. The total printing time for all four sections of the payload housing was 42 hours. After the split cores were printed the bonding area was lightly sanded and bonded with epoxy adhesives.

\section{Table 1}

The Print Setting Used to Print the Payload Housing Core

\begin{tabular}{|l|l|} 
Filament Diameter & $1.75 \mathrm{~mm}$ \\
Layer height & $0.2 \mathrm{~mm}$ \\
Infill & $10 \%$ \\
Extruder Temperature & $215^{\circ} \mathrm{C}$ \\
Number of shell & 2 \\
Printing speed & $90 \mathrm{~mm} / \mathrm{s}$
\end{tabular}




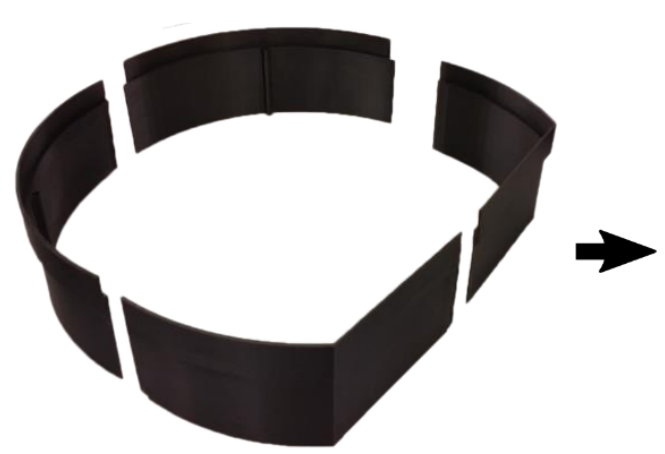

(a)

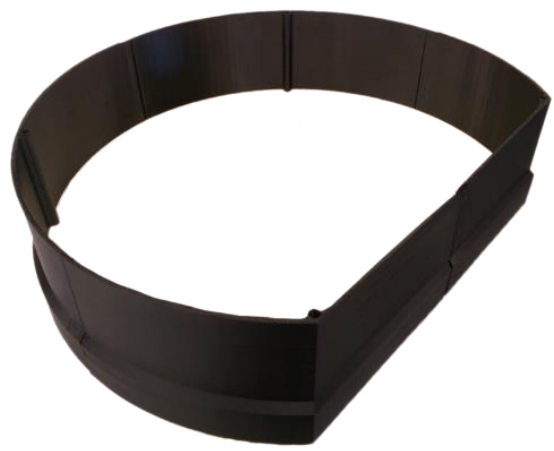

(b)

Figure 4. The printed payload housing core. (a) Four sections before bonding and (b) after bonding.

To adhere composite materials onto the PLA core, the entire surface of the core was lightly sanded. Composite prepreg materials required a higher temperature for the curing process (commonly $121^{\circ} \mathrm{C}-180^{\circ} \mathrm{C}$ ). However, the glass transition temperature $(\mathrm{Tg})$ of PLA is $60^{\circ} \mathrm{C}-65^{\circ} \mathrm{C}$. Therefore, there is a high chance that the additively manufactured PLA core is deformed during the composite material curing process. Therefore, a room temperature curing wet layup technique was used. A dry carbon fiber woven fabric (plain weave) was impregnated with epoxy resin and attached to the core. Four layers of composite material was laid up on the core. An envelope vacuum bag was used to consolidate the plies on the part with vacuum pressure of around $3.39 \mathrm{kPa}$ applied during the curing process.

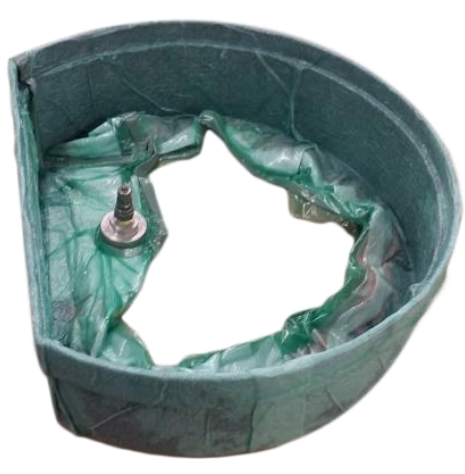

(a)

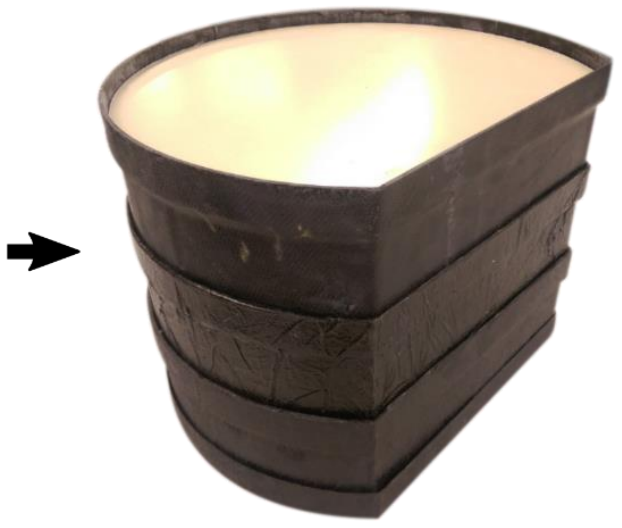

(b)

Figure 5. (a) Vacuum bagged carbon fiber prepreg on the printed core. (b) Carbon fiber reinforced composite payload housing assembly. 


\section{Cost Analysis}

Under the assumption that the estimated cost for the composite material for both traditional composite part manufacturing process and the method presented in this paper remained the same, the main cost difference between the two methods was the cost of the mold. If the payload housing was built using a traditional composite part manufacturing process with a metal mold, the stock size should be about $60.96 \mathrm{~cm}$ x $60.96 \mathrm{~cm}$ x $12.7 \mathrm{~cm}$. The cost of 6061 aluminum stock would be around $\$ 2100$ before the inclusion of shipping time and cost. The cost also does not include machining and fabrication cost of the mold. The estimated amount of material and time for printing the core with default print setting, shown in Table 1, was $600 \mathrm{~g}$ and 42 hours. Since $1 \mathrm{~kg}$ of PLA filament is about \$20 in market price, the cost for printing one section of the payload housings was around $\$ 12$. The process also required additional core surface sanding and bonding time. If the printer would have been large enough to print the entire housing at once, the printing time would decrease and there would be no core bonding time required. Also, utilizing the printed core allowed the part to have a sandwich structure which increased the flexural stiffness of the part. However, the surface of the payload housing was not as flawless as a part made using a metal mold. Also, only room temperature curing wet layup technique could be used for the composite material layup process due to low glass transition temperature (Tg) of PLA.

The carbon fiber reinforced composite rocket payload housing was successfully built and installed in a suborbital autonomous rocket, the EXOS SARGE as shown in Figure 6. Figure 7 shows the rocket payload housing installed in SARGE.

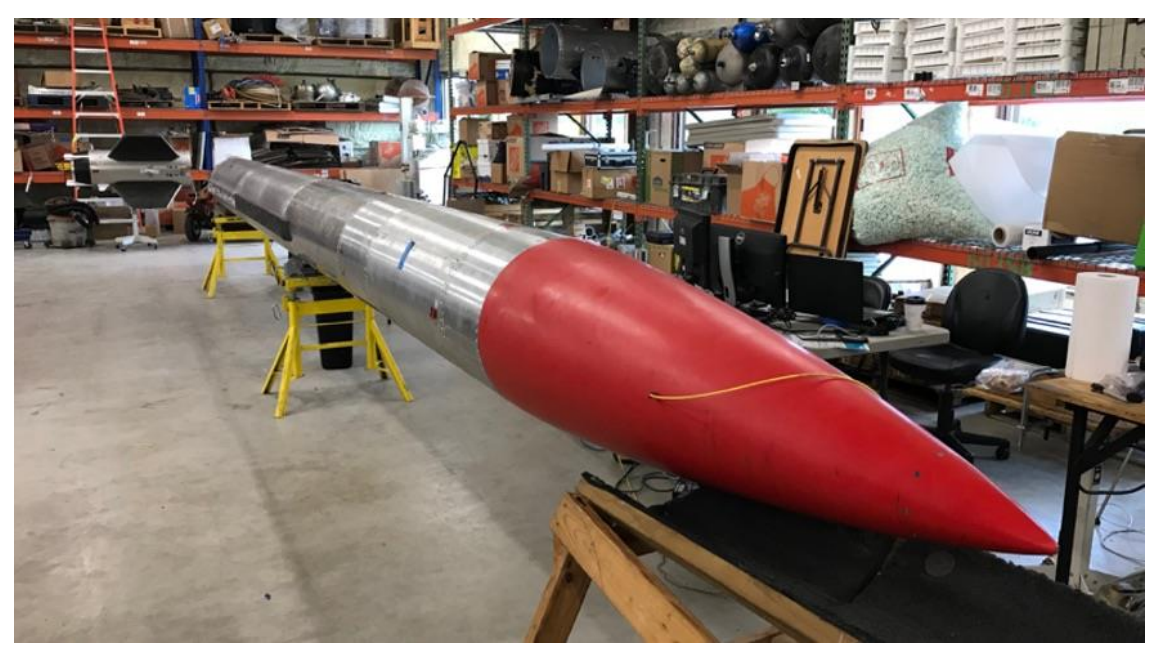

Figure 6. EXOS SARGE rocket. Adapted from "Exos Aerospace Reschedules First Suborbital Launch" by J. Foust, 2018, SpaceNews. 


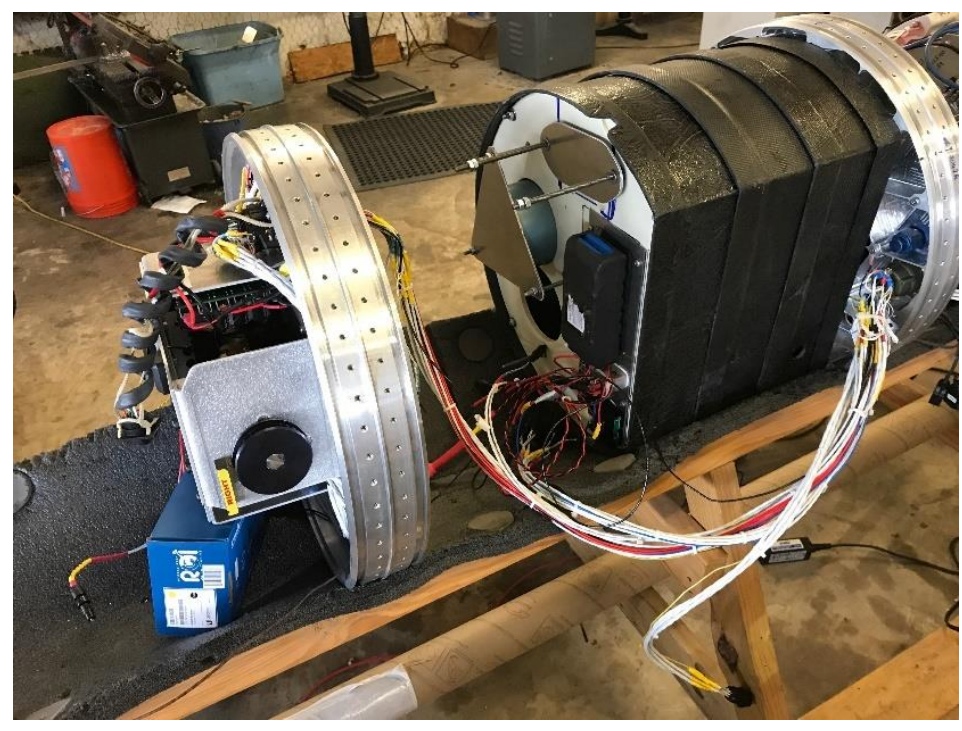

Figure 7. The payload housing assembly installed in EXOS SARGE rocket Adapted from "SARGE Update: 7/31/17. EXOS Aerospace" by L. Gregory, 2017, EXOS Aerospace.

\section{Conclusion}

This paper demonstrated the low-cost manufacturing process of a carbon fiber reinforced composite rocket payload housing using an additively manufactured PLA core and that the project could be done by undergraduate students under mentoring of experienced instructors. The payload housing was designed as a stackable cylindrical shape to maximize space efficiency and flexible configuration. Simple FEA was performed to determine the number of composite layers required on the core and simulated its performance. The core was additively manufactured using PLA thermoplastic polymer and the composite material was bonded on the surface of the core using wet layup technique. Different to traditional composite part manufacturing process, the composite part manufacturing process introduced in this paper did not use a metal mold which contributed to significant cost and time savings. Cost analysis showed that stock material for the payload housing metal mold was about $\$ 2100$ and the cost for printing three payload housing cores was $\$ 36$. However, the presented method has disadvantages in that the additively manufactured PLA core could not withstand composite prepreg curing temperature, so only room temperature cured wet layup technique can be used. Also, since there is no outer mold, the cured composite parts did not have a perfect surface quality. 


\section{References}

Barocio, E., Brenken, B., Favaloro, A., \& Pipes, R. B. (2017). Extrusion deposition additive manufacturing of composite molds for hightemperature applications. Proceedings of the Int. SAMPE Tech. Conf., Seattle (pp. 22-25).

Benchoff, B. (2017). Soluble molds for composite parts. Retrieved from https:/hackaday.com/2017/03/13/soluble-molds-for-composite-parts/

Bossi, R. H. (2006). NDE developments for composite structures. AIP Conference Proceedings (Vol. 820, No. 1, pp. 965-971). American Institute of Physics.

Brenken, B., Barocio, E., Favaloro, A., Kunc, V., \& Pipes, R. B. (2019). Development and validation of extrusion deposition additive manufacturing process simulations. Additive Manufacturing, 25, 218226.

Brodeur, D. R., Young, P. W., \& Blair, K. B. (2002). Problem-based learning in aerospace engineering education. Proceedings of the 2002 American society for engineering education annual conference and exposition (pp. 16-19).

Campbell, F. C. (2003). Manufacturing processes for advanced composites. New York, NY: Elsevier.

Coopersmith, J. (2011). The cost of reaching orbit: Ground-based launch systems. Space Policy, 27(2), 77-80.

Dubikovsky, S. (2016). Six sigma, senior capstone project, and ambiguity: students' reflections. Journal of Teaching and Education, 5(2), 481488.

Ellis, A., Carswell, L., Bernat, A., Deveaux, D., Frison, P., Meisalo, V., ... \& Tarhio, J. (1998). Resources, tools, and techniques for problem based learning in computing. ACM SIGCUE Outlook, 26(4), 41-56.

Foust, J. (2018). Exos Aerospace reschedules first suborbital launch. SpaceNews. Retrieved from https://spacenews.com/exos-aerospacereschedules-first-suborbital-launch

Galatas, A., Hassanin, H., Zweiri, Y., \& Seneviratne, L. (2018). Additive manufactured sandwich composite/ABS parts for unmanned aerial vehicle applications. Polymers, 10(11), 1262.

Gregory, L. (2017). SARGE update: 7/31/17. EXOS Aerospace. Retrieved from https://exosaero.com/2017/07/28/sarge-update-73117

Hicks, M. (2001). Design of a carbon fiber composite grid structure for the GLAST spacecraft using a novel manufacturing technique, ProQuest 
Dissertations and Theses.

Hmelo, C. E., \& Ferrari, M. (1997). The problem-based learning tutorial: Cultivating higher order thinking skills. Journal for the Education of the Gifted, 20(4), 401-422.

Kim, G., Barocio, E., Pipes, R. B., \& Sterkenburg, R. (2019). 3D printed thermoplastic polyurethane bladder for manufacturing of fiber reinforced composites. Additive Manufacturing, 29, 100809.

Koen, B. V. (2003). Discussion of the method: Conducting the engineer's approach to problem solving. Oxford, England: Oxford Univ.

Li, T., \& Wang, L. (2017). Bending behavior of sandwich composite structures with tunable 3D-printed core materials. Composite Structures, 175, 4657.

Maudsley, G. (1999). Roles and responsibilities of the problem based learning tutor in the undergraduate medical curriculum. Bmj, 318(7184), 657661.

McIntyre, C. (2002). Problem-based learning as applied to the construction and engineering capstone course at North Dakota State University. Proceedings 32nd Annual Frontiers in Education (Vol. 2, pp. F2DF2D). IEEE.

Peters, S. T. (2013). Handbook of composites. New York, NY: Springer Science \& Business Media.

Sairajan, K. K., \& Nair, P. S. (2011). Design of low mass dimensionally stable composite base structure for a spacecraft. Composites Part B:

Engineering, 42(2), 280-288.

Salim, A., Colin, C., Grah, A., \& Dreyer, M. E. (2010). Laminar bubbly flow in an open capillary channel in microgravity. International Journal of Multiphase Flow, 36(9), 707-719.

Schniepp, T. (n.d.). Additive manufactured composite tooling: Highperformance thermoplastics offer efficiencies and design flexibility. Retrieved from https://www.stratasys.com/-/media/files/white-papersnew/wp_fdm_additivelymanufacturedct_0317a-web.pdf

Tian, X., Liu, T., Yang, C., Wang, Q., \& Li, D. (2016). Interface and performance of 3D printed continuous carbon fiber reinforced PLA composites. Composites Part A: Applied Science and Manufacturing, 88, 198-205.

US Fed News Service. (2011). Students complete successful NASA zero-G experiments. Retrieved from http://search.proquest.com/docview/ 878569966? accountid $=13360$ 
